${ }^{1}$ Federal University of Bahia, Department of Clinical Dentistry, Salvador, Bahia, Brazil.

${ }^{2}$ Bahiana School of Medicine and Public Health and Federal University of Bahia, Department of Clinical Dentistry, Salvador, Bahia, Brazil.
Corresponding author: Emilena Maria Castor Xisto Lima Address: Rua Waldemar Falcão, n. 1906, Torre Paysage, apt. 1402 Horto Florestal

Salvador - Bahia CEP - 40295-010 Brazil

Tel: +55 (71) 99194-6656

E-mail: emilenalima@gmail.com

Received: March 23, 2019

Accepted: June 28, 2019

\section{Marginal adaptation of provisional crowns made of acrylic and bisacrylic resins using different impression materials}

\author{
Camilla Lopes Cerqueira ${ }^{1}$, Roniel Kappler ${ }^{1}$, Andrea \\ Araújo Nobrega Cavalcanti², Emilena Maria Castor \\ Xisto Lima ${ }^{2, *}$
}

Aim: To evaluate the marginal adaptation of provisional crowns made of acrylic and bisacrylic resins using different impression materials. Methods: a metal die and a matrix applied through a direct technique were used to fabricate the specimens. The impression materials used as a matrix were divided into four groups: Irreversible hydrocolloid (IH), laboratory silicone (LS), condensation silicone (CS), and addition silicone (AS). After the impression procedures, each matrix was loaded with the provisional prosthetic materials, Alike, Duralay, Protemp 4, and Structur $3(n=12)$. Marginal discrepancy was evaluated using a stereomicroscope at $\times 45$ magnification. The images obtained were transferred to the Corel Draw X7 program, and the distances from the cervical margins of the specimen to the reference lines at the metal die were measured vertically. The data were analyzed by using 2-way ANOVA followed by the Tukey test $(a=.05)$. Results: the acrylic resins had higher values of marginal discrepancy compared to the bisacrylic resins. A statistically significant difference was found between all impression materials, and the irreversible hydrocolloid presented higher values of discrepancy (303.28-613.31 um), whereas addition silicone had the lowest (48.61-190.06 $\mu \mathrm{m})$. Conclusions: the bisacrylic resins had a better marginal adaptation compared to the acrylic resins. The addition silicone promoted a better marginal adaptation of the provisional prosthetic materials tested, followed by condensation silicone, laboratory silicone, and irreversible hydrocolloid.

Keywords: Dental marginal adaptation. Dental restoration, temporary. Dental impression materials. 


\section{Introduction}

Temporary prostheses are needed to maintain gingival health, prevent the migration of abutment teeth, establish oclusal contact, and provide esthetic value during treatment. They also provide professionals with a prognosis as to the success of the final restoration in terms of its aesthetic and functional aspects ${ }^{1,2}$. Therefore, the exclusion or negligence of this step can lead to a failure of the final treatment ${ }^{3}$.

A marginal adaptation is one of the fundamental requirements of a fixed prosthesis because a poor marginal fit allows the formation of a gap between the restorative material and the prepared tooth ${ }^{1}$. Open marginal configurations encourage the microleakage of bacteria and their by-products owing to the dissolution of the luting agentes $^{4}$, and may predispose the tooth to caries or pulpitis. In addition, poorly adapted provisional prosthetic materials cause mechanical irritation to the surrounding tissues and enhance biofilm accumulation with subsequent periodontal problems ${ }^{1,5}$.

Choosing the appropriate combination of materials and techniques for the fabrication of a high-quality provisional restoration is important because the only difference between this and the definitive restoration should be the material used ${ }^{6}$. Interim restorations can be directly fabricated intraorally, indirectly in the laboratory, or with a direct-indirect technique when the restoration is formed extraorally and finalized intraorally ${ }^{7}$. Although an indirect technique produces a restoration with a superior marginal $\mathrm{fit}^{7,8}$, most dentists use a direct method with satisfactory results. A matrix planned for provisional fabrication may copy existing tooth contours from the mouth with a diagnostic cast ${ }^{9}$, or reproduce customized contours created through diagnostic waxing ${ }^{10}$. It has been further suggested that, when possible, this matrix should include at least one adjacent tooth on each side ${ }^{11}$.

The matrices applied for a direct technique are made of thermoplastic, vacuum-formed templates, irreversible hydrocolloid, or elastomeric impression materials ${ }^{12}$, although the matrix of choice depends upon the many variables of each particular situation. To select an appropriate material, it does help to have a feel for the classification of the impression materials, as well as concepts such as the working time, setting time, permanent deformation, and dimensional stability. There are certainly other important factors that influence the decision, such as ease of manipulation, taste, and tackiness, but they have thus far eluded quantitative measurement ${ }^{13}$. In fact, an accurate reproduction of the preparation margins in an impression is a necessary requirement for achieving a good marginal quality ${ }^{14}$.

The materials available for fabricating provisionally fixed partial dentures include autopolymerizing polymethyl methacrylate, polyethylene methacrylate, polyvinyl methacrylate, urethane methacrylate, bis-acryl, and microfilled resins ${ }^{15}$. Historically, autopolymerizing polymethyl methacrylate resin (PMMA) has been the most popular material and is widely used by clinicians, although during the last several years, temporary bis-acryl composite materials have been introduced and are rapidly gaining acceptance ${ }^{15}$ owing to such benefits as ease of use ${ }^{3}$, better color stability ${ }^{16}$, resistance to wear $^{17}$, and low exothermic heat ${ }^{18}$. 
Studies conducted to assess the degree of marginal gap formation of provisional materials have shown contradictory results. Some studies have indicated that acrylic resins have lower marginal discrepancies compared to bisacrylic resins, some of which have shown a comparable fit between both types, whereas other studies have demonstrated bis-acryl composite resin to be superior to acrylic resin ${ }^{5,17,19}$.

Thus, the aim of this study was to evaluate the marginal adaptation of provisional crowns made of acrylic and bisacrylic resins using different impression materials (irreversible hydrocolloid, laboratory silicone, condensation silicone, and addition silicone). The null hypothesis was that there was no difference between marginal adaptations of these restorative materials and between these impression materials.

\section{MATERIALS AND METHODS}

The materials used in this study are described in Tables 1 and 2.

Table 1. Impression materials used in the present study.

\begin{tabular}{lcc}
\hline Impression material & Product & Manufacturer \\
\hline Irreversible hydrocolloid & Hydrogum 5 & Zhermack SpA, Germany \\
\hline Laboratory silicone & Zetalabor & Zhermack SpA, Badia Polesine, RO, Italy \\
\hline Condensation silicone & Zetaplus Putty/Oranwash & Zhermack SpA, Badia Polesine, RO, Italy \\
\hline Addition silicone & Elite HD/Putty Regular & Zhermack SpA, Badia Polesine, RO, Italy \\
\hline
\end{tabular}

Table 2. Provisional prosthetic materials used in the present study.

\begin{tabular}{|c|c|c|c|}
\hline Product name & Material classification & Composition & Manufacturer \\
\hline Alike & $\begin{array}{l}\text { Polymethymethacrylate } \\
\text { (PMMA) }\end{array}$ & $\begin{array}{l}\text { Barium silicate glass, benzoyl } \\
\text { peroxide, dimethylp-toluidene, } \\
\text { methacrylate polymer, methyl } \\
\text { methacrylate, ethyl-2-cyano-3- } \\
\text { diphenylacrylate, methanol }\end{array}$ & $\begin{array}{c}\text { GC América, Alsip - IL, } \\
\text { EUA }\end{array}$ \\
\hline Duralay & $\begin{array}{l}\text { Polymethymethacrylate } \\
\text { (PMMA) }\end{array}$ & $\begin{array}{l}\text { Copolymer of plasticizable } \\
\text { methacrylate, Monomer of } \\
\text { methylmethacrylate, Paraffin, } \\
\text { mineral oil }\end{array}$ & $\begin{array}{l}\text { Reliance, Cotia, São } \\
\text { Paulo, Brasil }\end{array}$ \\
\hline Structur 3 & Bis-acryl composite & $\begin{array}{l}\text { Bis-GMA, BHT, amines, benzoyl } \\
\text { peroxide, dimethacrylates, glass } \\
\text { particles }\end{array}$ & $\begin{array}{c}\text { VOCO SmbH Cuxhaven, } \\
\text { Alemanha }\end{array}$ \\
\hline Protemp 4 & Bis-acryl composite & $\begin{array}{c}\text { Dimethacrylate polymer, Bis-GMA, } \\
\text { zirconium, silica and silane particles, } \\
\text { pigments }\end{array}$ & $\begin{array}{l}\text { 3M-ESPE, Seefeld, } \\
\text { Alemanha }\end{array}$ \\
\hline
\end{tabular}

\section{Specimen preparation}

An in vitro method was used to simulate a direct clinical technique in which a provisional crown was made directly on the prepared tooth using different impression materials as a matrix (Table 1). Mandibular left first molar prepared for a complete 
metaloceramic crown with a 1-mm chamfer finish line and a taper of approximately 5 degrees was cast in a base metal alloy and adapted to the left mandibular hemi-arch (Fig. 1). A standard crown was fabricated for the prepared die to represent the form of the tooth prior to preparation (Fig. 2). A matrix planned for provisional fabrication was used to copy the contours from the standard crown adapted to the metal die. This matrix was extended onto at least one tooth adjacent to the teeth being restored. The impression materials were divided into four groups: irreversible hydrocolloid $(I H)$, laboratory silicone (LS), condensation silicone (CS), and addition silicone (AS). Twelve impressions were taken for each impression material. This impression served as a matrix for making the provisional crowns for all materials applied: Alike, Duralay, Protemp 4, and Structur $3(\mathrm{n}=12)$. A verticulator (Bio-art Equipamentos Odontológicos Ltda., São Carlos - SP, Brazil) was used to standardize the path of insertion and removal of the partial stock tray and the applied force (Fig. 2).

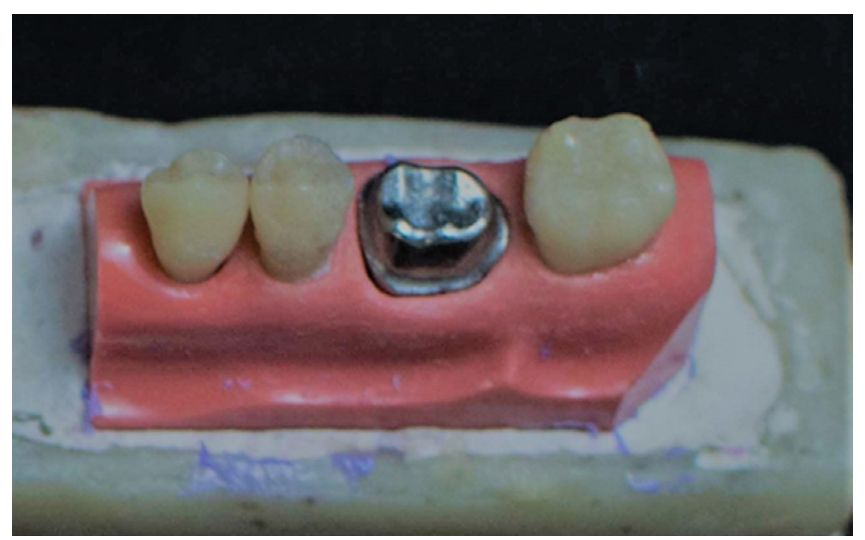

Figure 1. The metal die (copy of the mandibular left first molar prepared for a complete metaloceramic crown) adapted to the left mandibular hemi-arch.

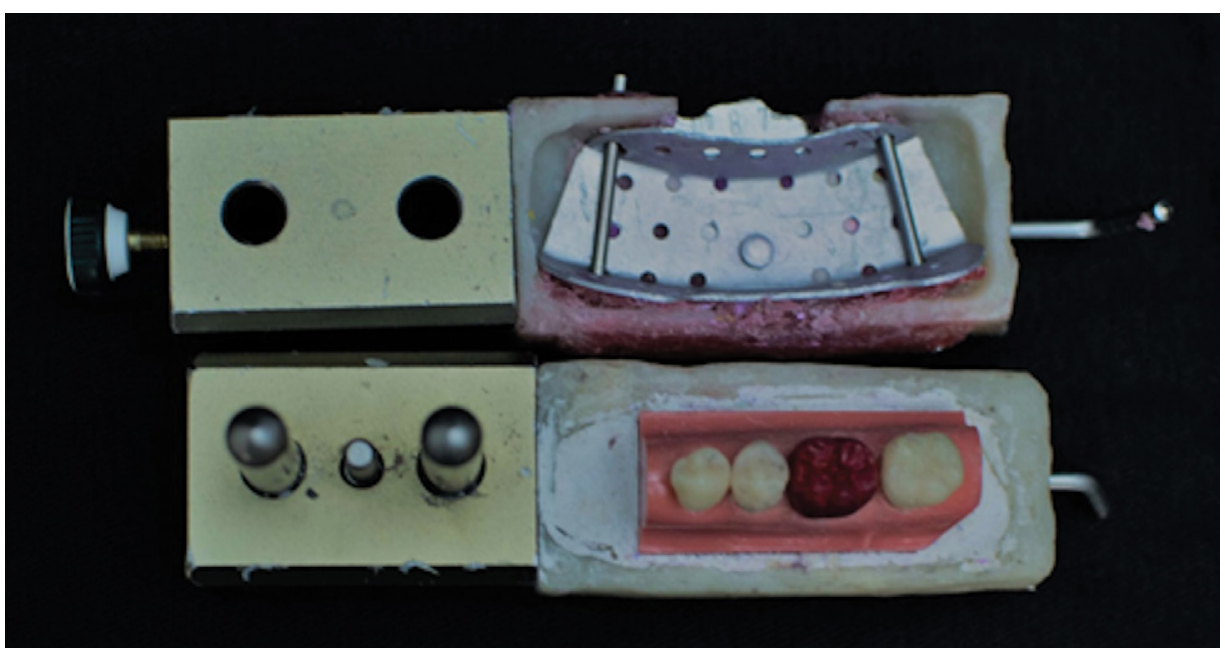

Figure 2. The partial stock tray and standard crown on the metal die in the left mandibular hemi-arch. Both were adapted to the upper and lower parts of the verticulator, respectively. 
Group IH: The irreversible hydrocolloid (IH), (Hydrogum 5, Zhermack, BadiaPolesine $\mathrm{RO}$, Italy) was used at a ratio of 1:1; the powder was dispensed into water in a rubber vat and manipulated using a plastic spatula until homogenization. The irreversible hydrocolloid was loaded into the partial stock tray and seated on the standard crown with the aid of the verticulator, where it remained locked for 2 min until the gelation was complete.

Group LS: Laboratorial silicone (Zetalabor, Zhermack, BadiaPolesine - RO, Italy) was proportioned and manipulated following the manufacturer's instructions. The material was then loaded into the stock tray and seated on the standard crown with the aid of the verticulator. It remained locked until complete polymerization of the laboratory silicone.

Group CS: Condensation silicone (Zetaplus, Zhermack, BadiaPolesine - RO, Italy) was used, and a putty material was proportioned and manipulated following the manufacturer's instructions, and loaded into the stock tray. A light paste and catalyst were placed on a glass plate (at a 1:1 ratio) and handled using a \#24 spatula. The light-body material was dispensed using an elastomer syringe on the standard crown. Thereafter, the stock tray loaded with the putty material was seated on the standard crown, and the verticulator was locked until complete polymerization of the condensation silicone.

Group AS: Addition silicone (Elite HD, Zhermack, BadiaPolesine - RO, Italy) was used at a 1:1 ratio. The putty material was provided and handled following the manufacturer's instructions and loaded into the stock tray. The light-body material was dispensed using a dispenser gun and compatible mixing tip on the standard crown. The stock tray loaded with the material was seated on the standard crown and the verticulator was locked until complete polymerization of the addition silicone.

Next, the metal die (copy of the tooth prepared) was lubricated (Vaseline; Quimidrol) to prevent adhesion to the resin samples. The acrylic resins (Duralay and Alike) were dispensed and mixed according to the manufacturer's instructions, and placed in the matrices with the aid of a manipulating spatula (\#24). The bisacryl composites (Protemp 4 and Structur 3) were inserted into the matrices using a dispenser gun and compatible mixing tips. The resin-filled impression was seated on the metal die with aid of the verticulator, which remained locked during polymerization.

Before complete polymerization (plastic phase), any excess material was trimmed from the margins of the provisional restorations using a scalpel blade (15c). The test specimens were kept in a closed, dry container for $24 \mathrm{~h}$ until an analysis of the marginal discrepancy was conducted.

\section{Analysis of marginal discrepancy}

The provisional crowns were adapted to the metal die with the aid of a "C" clamp (Metasul, Braço do Norte - SC, Brazil) (Fig. 4) and kept at a standardized position during the analysis in a stereomicroscope lupe (Optima MDCE-5a , 2.0, Hiperquímica, Santo André - SP, Brazil).

Photographs at 45X magnification were obtained from the buccal, lingual, mesial, and distal surfaces, and the images were transferred to Corel Draw $X 7$ program. The mar- 


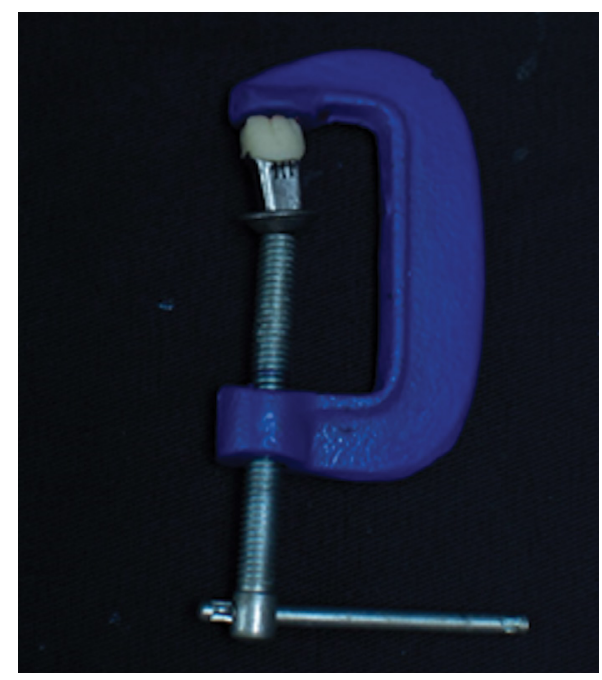

Figure 3. Temporary crown adapted to the metal die with a "C" clamp.

ginal discrepancy of the provisional crowns was determined by measuring the space (marginal opening) between the margin of the provisional crowns and the finish line of the metal die. For each provisional crown, the measurements were made at four vertical reference lines previously marked at the midpoint of the metal die finish line at four locations to represent the buccal, lingual, mesial, and distal surfaces of the die. The measurements were made three times along the long axis of the die at each of the four reference points. All procedures were performed by one operator calibrated.

\section{Statistical analysis}

The amounts of marginal discrepancy were compared among the 4 provisional restoration materials and impression materials with a 2- way analysis of variance (ANOVA) followed by the Tukey test for multiple comparisons ( $a=.05)$. The analyses were conducted using the statistical program, SAS, version 9.1 (SAS Institute, Cary, NC, USA).

\section{RESULTS}

Table 3 shows the mean and standard deviation of the marginal discrepancy values obtained.

Table 3. Mean (standard deviation) of the marginal discrepancy $(\mu \mathrm{m})$.

\begin{tabular}{lcccc}
\hline $\begin{array}{l}\text { Impression materials / } \\
\text { Resins }\end{array}$ & Alike & Duralay & Protemp 4 & Structur 3 \\
\hline Irreversible hydrocolloid & $613.31(19.53)^{\mathrm{Aa}}$ & $605.08(25.97)^{\mathrm{Aa}}$ & $334.35(24.99)^{\mathrm{Ab}}$ & $303.28(16.76)^{\mathrm{Ac}}$ \\
\hline Laboratorial silicone $^{\mathrm{Ba}}$ & $440.92(18.61)^{\mathrm{Ba}}$ & $387.21(24.69)^{\mathrm{Bb}}$ & $237.90(11.82)^{\mathrm{Bc}}$ & $238.87(15.16)^{\mathrm{Bc}}$ \\
\hline Condensation silicone $^{\mathrm{Ca}}$ & $258.77(19.48)^{\mathrm{Ca}}$ & $250.85(16.71)^{\mathrm{Ca}}$ & $133.86(12.49)^{\mathrm{Cb}}$ & $104.00(4.79)^{\mathrm{Cc}}$ \\
\hline Addition silicone & $190.06(9.74)^{\mathrm{Da}}$ & $192.83(6.01)^{\mathrm{Da}}$ & $73.58(6.68)^{\mathrm{Db}}$ & $48.61(7.08)^{\mathrm{Dc}}$ \\
\hline
\end{tabular}

Mean followed by distinct letters represents a significant difference (Anova 2-way/Tukey, a=.05)). Upper case letters compare the impression materials within each level of the resin factor. Lower case letters compare resins within each level of the impression material factor. 
The statistical analysis showed the significance of the interaction between the main factors impression material $x$ resin $(p<0.0001)$, demonstrating dependence between the levels of one factor on the outcome of another. Statistically significant differences among the impression materials were found at all resin factor levels. Irreversible hydrocolloid was shown to have the highest discrepancy, followed by laboratory silicone, condensation silicone, and addition silicone. For the resins, it was observed that when irreversible hydrocolloid, condensation silicone, or addition silicone was applied as the impression material, the acrylic resins Alike and Duralay showed statistically similar and significantly higher values than the bisacrylic resins Protemp 4 and Structur 3, presenting statistical differences among them. For the laboratory silicone material, the acrylic resins Alike and Duralay presented statistically significant differences between them; however, both showed a superior discrepancy compared to the bisacryl resins Protemp 4 and Structur 3.

\section{DISCUSSION}

In this study, 4 provisional restorative materials and 4 impression materials were evaluated for marginal fit. The results indicate that the null hypothesis was rejected. The accuracy of fit has been extensively investigated in the dental literature. Marginal openings of between 100 and $200 \mathrm{~mm}$ are considered clinically acceptable with regard to longevity ${ }^{20-22}$. However, some authors have considered a marginal discrepancy between 50 and $120 \mu \mathrm{m}$ to be within the range of clinical acceptance ${ }^{23-25}$. Holmes et al. ${ }^{26}$ (1989) described this divergence of values between various studies as resulting from the fact that, unlike the physical and mechanical properties of the materials applied, the fit of a restoration has never been strictly defined. The reference points for the measurements and the descriptive terminology defining a fit vary considerably among investigators.

In the present study, some groups, namely, addition silicone for all resins, and condensation silicone for bisacryl composites (table 3) were within the clinically acceptable threshold established in the literature ${ }^{20-22}$. However, the other groups presented values above these limits. The variations in the results of this study as compared with other studies could be because of the differences in the materials and fabrication techniques applied. A direct relationship exists between an initially poor marginal adaptation and the dissolution of cement (with a resultant microleakage) ${ }^{27}$, and damage to the adjacent tissues ${ }^{28}$.

The bisacrylic resins showed a significantly lower marginal discrepancy when compared with the acrylic resins. Young et al. ${ }^{29}$ (2001) compared the quality of the provisional restorations fabricated by dental students using two materials (bis-acryl composite resin and PMMA), and found that the bis-acryl composite resin (Integrity) was significantly superior to PMMA (C\&B Resin and Snap) as a provisional restorative material, including marginal adaptation. Tjan et al. ${ }^{5}$ (1997) evaluated the vertical discrepancies of the margins for complete crowns and indicated that provisional crowns fabricated using Protemp Garant (bys-acryl composite) and Splintline (EMA) recorded the least marginal discrepancies. These results corroborate with those of the present study despite the different materials used. 
This difference in adaptation between acrylic and bisacrylic resins can be attributed to the higher polymerization shrinkage of the acrylic resins. Deficiencies can occur when autopolymerizing acrylic resin is used owing to a dimensional contraction because of the difference in density between the polymer and monomer applied ${ }^{30}$. Temporary crowns maintained in water at $20-30^{\circ} \mathrm{C}$ for $10 \mathrm{~min}$ help to obtain a better marginal fit ${ }^{31}$. This technique decreases the monomer content and reduces the chance of irritation from the free monomer content, which may directly influence the polymerization shrinkage, and consequently the marginal adaptation. Moreover, a bis-acrylic or bis-acrylate composite differs from a methacrylate resin, but is similar to a composite restorative material because it is made of a bis-acryl resin and inorganic fillers, the latter of which reduces polymerization shrinkage ${ }^{32}$. It has been stated that volumetric polymerization shrinkage for PMMA is $6 \%$, compared with $1-4 \%$ for composite materials ${ }^{33}$.

The most common materials used for the fabrication of provisionals are polymethylmethacrylate (PMMA) and composite-based resin (CBR) ${ }^{34}$. The PMMA comes in the form of a polymer, which is a powder and monomer in liquid form that has to be hand mixed. The CBR comes in the form of an auto-mixed paste or in paste tubes. PMMA is chemically polymerized, whereas CBR is available as a chemically or light cured material $^{34}$. One attractive aspect of a bisacryl composite is its convenient, cartridge-based dispensing system, which should result in a more accurately proportioned and consistent mix $^{29}$. This innovative approach may have contributed to the superior results credited to Protemp 4 and Structur 3.

However, Wang et al. ${ }^{17}$ (1989) observed that acrylic resin and bisacrylic produce similar marginal gaps. They indicated that Alike e Protemp produced the best fitting crowns, exhibiting respective marginal gaps of 90.7 and $94.2 \mathrm{~mm}$.

Few studies in the dental literature have compared the accuracy of the impression material used to fabricate a temporary crown. In this study, a direct technique was used with different impression materials, and a significant difference in marginal discrepancy was found among all of them. It was verified that the impression material influenced the accuracy of the temporary crowns. Addition silicone promoted the smallest marginal discrepancy in the provisional crowns, followed by condensation silicone, laboratory silicone, and finally, irreversible hydrocolloid. Addition-cured silicone rubber is considered the most dimensionally stable impression material, which is set using an addition-cured polymerization reaction, with no by-product produced during cross-linkage, resulting in an extremely stable impression ${ }^{13}$.

Irreversible hydrocolloid promoted the highest marginal discrepancy in the provisional crowns. This material has two major disadvantages, firstly, very poor dimensional stability because of the ready loss or imbibition of water on standing in dry or wet environments respectively. Secondly, low tear resistance which can be a real problem when attempting to record the gingival sulcus $^{13}$.

Faria et al. ${ }^{35}$ (2008) evaluated the the accuracy of different impression materials used for fixed partial dentures (irreversible hydrocolloid, condensation silicone, addition silicone, polyether, and polysulfide), and verified that different impression materials and techniques influence the accuracy of the stone casts in such a way 
that polyether, polysulfide, and addition silicone, when following a single-phase technique, are more accurate than the other materials ${ }^{35}$. An accurate stone cast is indispensable for the fabrication of a crown or bridge, and the choice of the impression material is a vital step.

Vitti et al. ${ }^{36}$ (2013) compared the dimensional accuracy of casts made using three impression techniques with addition and condensation silicone, and concluded that stone casts made from addition silicone is also dimensionally more accurate, corroborating the results of the present study. However, an analysis of the accuracy of the impression material in a stone cast differs from that of a specimen ${ }^{36}$. As with the present study, the authors also used putty and a light-body material. The high filler loading of the putty was initially devised to reduce the effects of polymerization shrinkage. Putty is commonly combined with a low viscosity silicone when recording an impression to produce more accurate results ${ }^{13}$.

This study attempted to highlight some of the issues related to the marginal opening of the provisional materials available in the market associated to a direct tecnhnique used to fabricate provisional restorations with diferentt impression materials. However, further studies are needed for the development of more durable and accurate materials for provisional restorations.

In conclusion, bisacrylic resins showed a better marginal adaptation than acrylic resins. Addition silicone promoted a better marginal fit of the provisional prosthetic materials tested, followed by condensation silicone, laboratory silicone, and irreversible hydrocolloid.

\section{REFERENCES}

1. Nejatidanesh F, Lotfi HR, Savabi O. Marginal accuracy of interim restorations fabricated from four ínterim autopolymerizing resins. J Prosthet Dent. 2006 May;95(5):364-7.

2. Haselton DR, Diaz-Arnold AM, Vargas MA. Flexural strength of provisional crown and fixed partial denture resins. J Prosthet Dent. 2002 Feb;87(2):225-8.

3. Burns DR, Beck DA, Nelson SK. A review of selected dental literature on contemporary provisional fixed prosthodontic treatment: Report of the Committee on Research in Fixed Prosthodontics of the Academy of Fixed Prosthodontics. J Prosthet Dent. 2003 Nov;90(5):474-97.

4. Rastogi A, Kamble V. Comparative analysis of the clinical techniques used in evaluation of marginal accuracy of cast restoration using stereomicroscopy as gold standard. J Adv Prosthodont. 2011 Jun;3(2):69-75. doi: 10.4047/jap.2011.3.2.69.

5. Tjan AHL, Castelnuovo J, Shiotzu G. Marginal fidelity of crowns fabricated from six proprietary provisional materials. J Prosthet Dent. 1997 May;77(5):482-5.

6. Reshad M, Cascione D, Kim T. Anterior provisional restorations used to determine form, function, and esthetics for complex restorative situations, using all-ceramic restorative systems. J Esthet Restor Dent. 2010 Feb;22(1):7-16. doi: 10.1111/j.1708-8240.2009.00305.x.

7. Dumbrigue HB. Composite indirect-direct method for fabricating multiple-unit provisional restorations. J Prosthet Dent. 2003 Jan;89(1):86-8.

8. Regish KM, Sharma D, Prithviraj DR. Techniques of fabrication of provisional restoration: An overview. Int J Dent. 2011;2011:134659. doi: 10.1155/2011/134659. 
9. Clements WG. Predictable anterior determinants. J Prosthet Dent. 1983 Jan;49(1):40-5

10. Amet EM, Phinney TL. Fixed provisional restorations for extended prosthodontic treatment. J Oral Implantol. 1995;21(3):201-6.

11. Konstantinidis I, Kotsakis G, Pallis K, Walter MH. A novel technique for the direct fabrication of fixed interim restorations. J Prosthet Dent. 2013 Mar;109(3):198-201. doi: 10.1016/S0022-3913(13)60044-X.

12. Ayuso-Montero R, Martinez-Gomis J, Lujan-Climent M, Salsench J, Peraire M. Influence of matrix type on surface roughness of three resins for provisional crowns and fixed partial dentures. J Prosthodont. 2009 Feb;18(2):141-4. doi: 10.1111/j.1532-849X.2008.00392.x.

13. Wassell RM, Barker D, Walls AWG. Crowns and other extra-coronal restorations: Impression materials and technique. Br Dent J. 2002 Jun 29;192(12):679-84, 687-90.

14. Hamalian TA, Nasr E, Chidiac JJ. Impression material in fixed prosthodontics: Influence of choice on clinical procedure. J Prosthodont. 2011 Feb;20(2):153-60. doi: 10.1111/j.1532-849X.2010.00673.x.

15. Christensen GJ. The fastest and best provisional restorations. J Am Dent Assoc. 2003 May; 134(5):637-9

16. Sham ASK, Chu FCS, Chai J, Chow TW. Color stability of provisional prosthodontic material. J Prosthet Dent. 2004 May;91(5):447-52.

17. Wang K, Moore BK, Coodacre C, Sifdrfe ML, Andres CJ. A Comparison of resins for fabricating provisional fixed restorations. Int J Prosthodont. 1989 Mar-Apr;2(2):173-84.

18. Driscoll CF, Woolsey G, Ferguson WM. Comparison of exothermic release during polymerization of four materials used to fabricate interim restorations. J Prosthet Dent. 1991 Apr;65(4):504-6.

19. Koumjian JH, Holmes JB. Marginal accuracy of provisional restorative materials. J Prosthet Dent. 1990 Jun;63(6):639-42.

20. Fransson B, Oilo G, Gjeitanger R. The fit of metal-ceramic crowns, a clinical study. Dent Mater. 1985 Oct;1(5):197-9.

21. Karlsson S. The fit of Procera titanium crowns. An in vitro and clinical study. Acta Odontol Scand. 1993 Jun;51(3):129-34.

22. McLean JW, Fraunhofer JA von. The estimation of cement film by an in vivo technique. Br Dent J. 1971 Aug 3;131(3):107-11.

23. Abduo J, Lyons K, Swain M. Fit of zirconia fixed partial denture: A systematic review. J Oral Rehabil. 2010 Nov;37(11):866-76. doi: 10.1111/j.1365-2842.2010.02113.x.

24. Colpani JT, Borba M, Della Bona A. Evaluation of marginal and internal fit of ceramic crown copings. Dent Mater. 2013 Feb;29(2):174-80. doi: 10.1016/j.dental.2012.10.012.

25. Habib SR, Asiri W, Hefne MJ. Effect of anatomic, semi-anatomic and non- anatomic occlusal surface tooth preparations on the adaptation of zirconia copings. J Adv Prosthodont. 2014 Dec;6(6):444-50. doi: 10.4047/jap.2014.6.6.444.

26. Holmes JR, Bayne SC, Holland GA, Sulik WD. Considerations in measurement of marginal fit. J Prosthet Dent. 1989 Oct;62(4):405-8.

27. Meyer Filho A, Vieira LCC, Araujo E, Baratieri LN. Ceramic inlavs and onlavs: Clinical procedures for predictable results. J Esthet Restor Dent. 2003;15(6):338-51; discussion 352.

28. Karlsson S. A clinical evaluation of fixed bridges, 10 years following insertion. J Oral Rehabil. 1986 Sep;13(5):423-32.

29. Young HM, Smith CT, Morton D. Comparative in vitro evaluation of two provisional restorative materials. J Prosthet Dent. 2001 Feb;85(2):129-32. 
30. Patras M, Naka O, Doukaudakis S, Pissiots A. Management of provisional restorations deficiencies: A literature review. J Esthet Restor Dent. 2012 Feb;24(1):26-38. doi: 10.1111/j.1708-8240.2011.00467.x.

31. Dhillon N, Kumar M, D'Souza DSJ. Effect of water temperature and duration of immersion on the marginal accuracy of provisional crowns. Med J Armed Forces India. 2011 Jul;67(3):237-40. doi: 10.1016/S0377-1237(11)60049-X.

32. Darvell, B.W. Resin restorative materials. Materials Science for Dentistry. 9th ed. Cambridge: Woodhead Publishing; 2009. 103p.

33. Lepe X, Bales DJ, Johnson GH. Retention of provisional crowns fabricated from two materials with the use of four temporary cements. J Prosthet Dent. 1999 Apr;81(4):469-75.

34. Al Rifaiy MQ. Evaluation of vertical marginal adaptation of provisional crowns by digital microscope. Niger J Clin Pract. 2017 Dec;20(12):1610-1617. doi: 10.4103/1119-3077.196083.

35. Faria AC, Rodrigues RC, Macedo AP, Mattos Mda G, Ribeiro RF. Accuracy of stone casts obtained by different impression materials. Braz Oral Res. 2008 Oct-Dec;22(4):293-8.

36. Vitti RP, da Silva MA, Consani RL, Sinhoreti MA. Dimensional accuracy of stone casts made from silicone-based impression materials and three impressions techniques. Braz Dent J. 2013 Sep-Oct;24(5):498-502. doi: 10.1590/0103-6440201302334. 